\title{
MYSTERY PHOTO
}

\section{DECEMBER 2002 MYSTERY PHOTO}

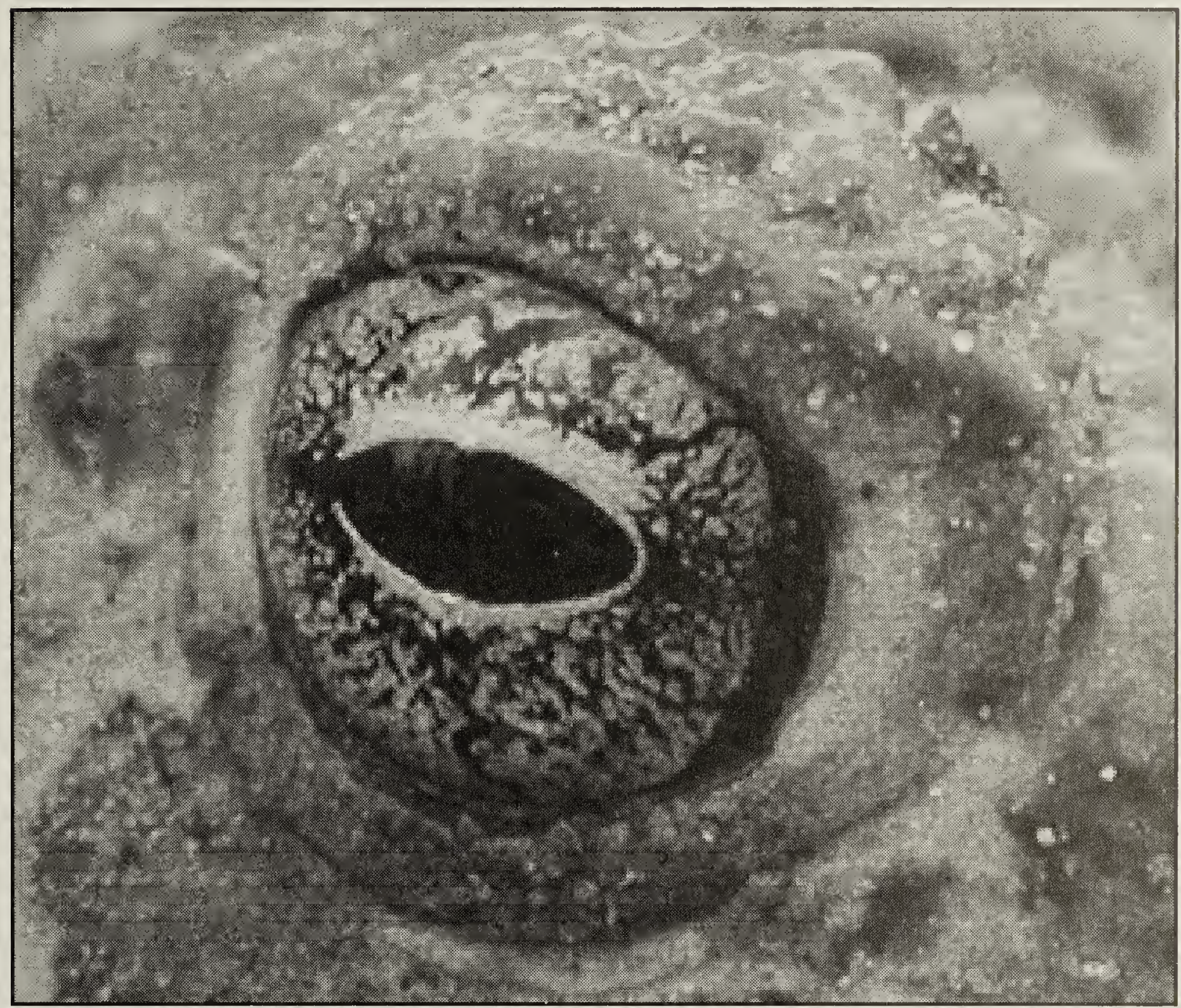

Who is this creature eyeing the grassland east of Liebenthal, SK in mid-June?

Photograph by Joanne Marchand

\section{ANSWER TO SEPTEMBER 2002 MYSTERY PHOTO}

Several people sent Blue Jay correct guesses about September's mystery object: Ruth Griffiths, David Sterling and Ernie Kuyt, gracing us with all sorts of interesting terms for it such as fibrous plate, horny flat knob, nose cone and horny process on the culmen. Spencer Sealy provided readers with the following details about the structure, as well as additional name, "bill horn".

The object depicted in the September mystery photo is a maxillary horn or bill

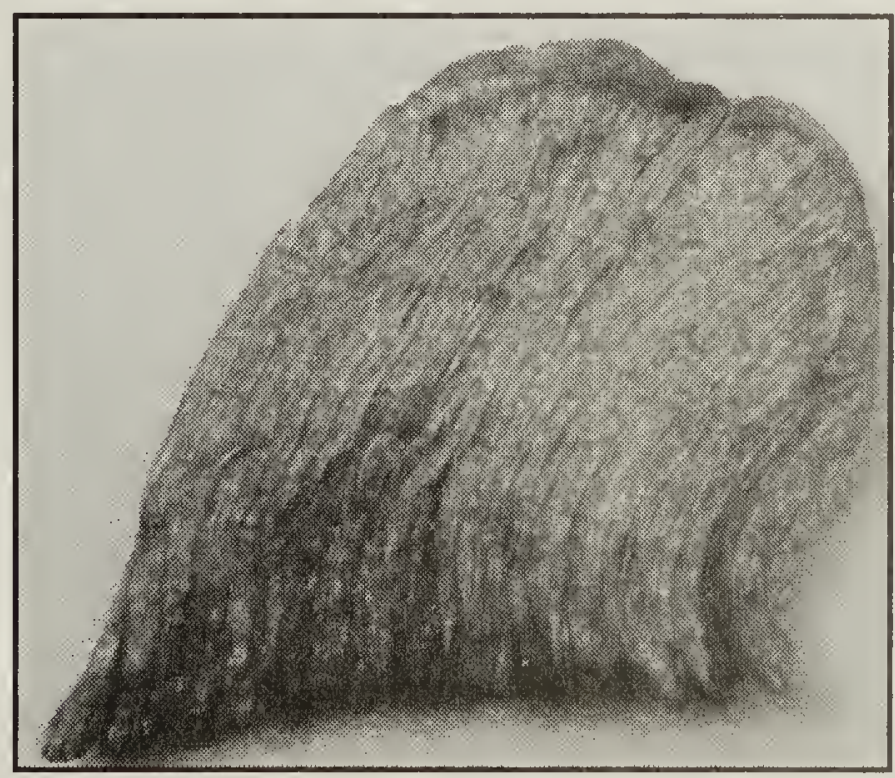

Bill horn shed by an American White Pelican

Thijs Kuiken 
horn that was shed from the upper mandible (bill) of a female or male American White Pelican. Unique to the pelicans (Family Pelecanidae), these bill horns are composed of several erect horny plates that develop annually along with the alternate (nuptial) plumage prior to nesting; they are shed around the time the young hatch. ${ }^{1,2}$ Shed bill horns probably drop into the water or to the ground in the nesting colony, in this case on an island in Doré Lake.

The horn apparently serves as a signalling device during and in the aftermath of pair formation. 2. 3 Paired birds aggressively defend potential nest sites within the colony and frequent, vigorous jabs and snappings of the bills bring the bills into contact with one another. The jabs are directed toward the horn on the bill; this "target" structure may reduce the likelihood that the jabbing bills will puncture the fleshy pouch necessary for foraging. ${ }^{2}$

Although the bill horn may be essential for successful nesting, it presents a downside for pelicans in a world altered by humans. While conducting research over the years at Delta Marsh, along the south shore of Lake Manitoba, I have encountered at least three dead pelicans with their bills entangled in discarded commercial fishing nets. Inspection revealed that the birds were caught by netting wound around the bill horns. The nets, draped over a side and back of the birds, impaired their mobility and prevented them from foraging. Death likely came slowly.

1. Campbell, B., and E. Lack (Eds.). 1985. A Dictionary of Birds. T and AD Poyser, Calton.

2. Knopf, F.L. 1975. Schedule of presupplemental molt of White Pelicans with notes on the bill horn. Condor 77:356-359.

3. Schaller, G.B. 1964. Breeding behavior of the White Pelican at Yellowstone Lake, Wyoming. Condor 66:3-23.

- Spencer G. Sealy, Department of Zoology, University of Manitoba, Winnipeg, MB R3T 2N2

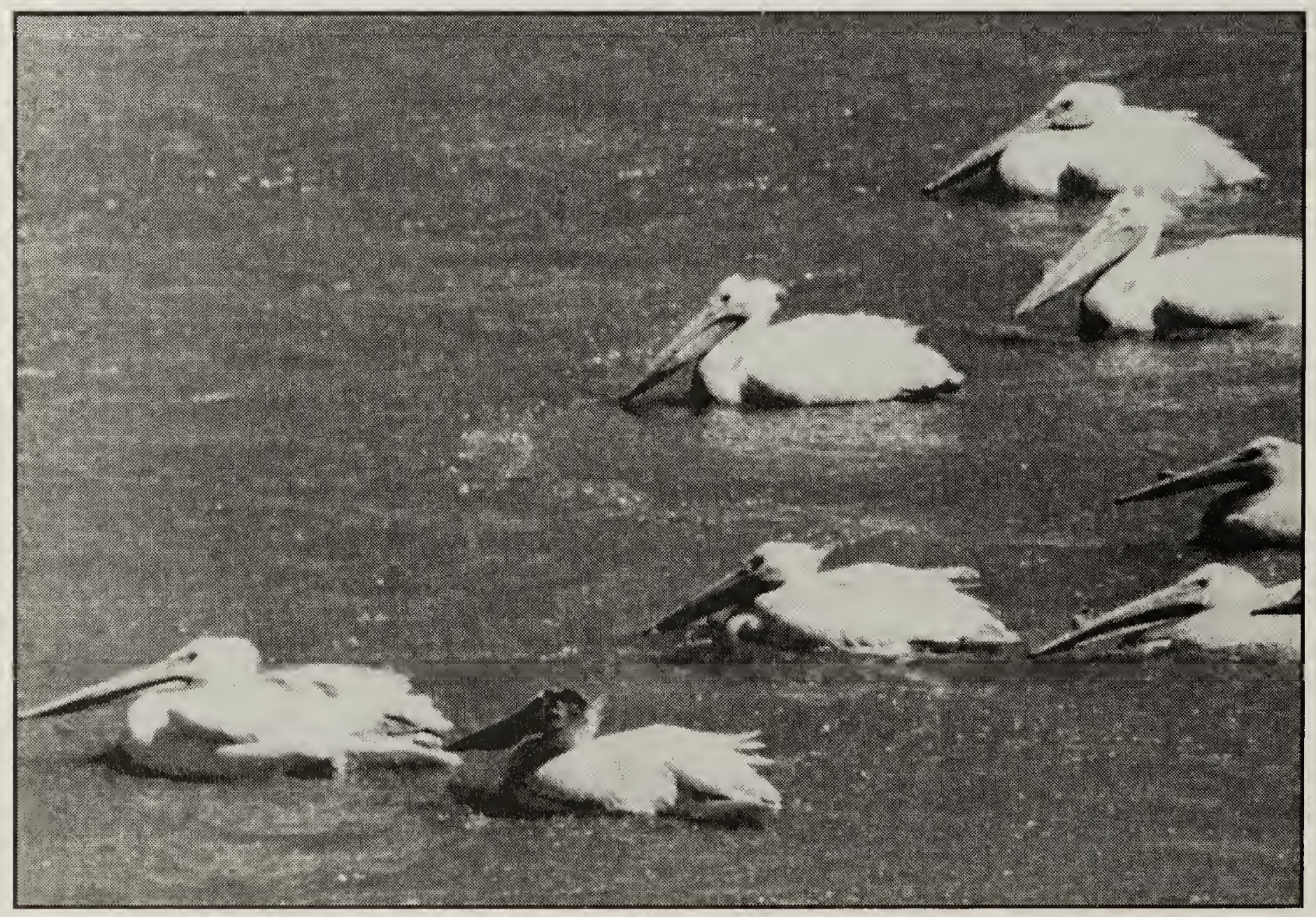

